\title{
The Correlation between Enrolment Criteria and Students' Success in the Study of Medicine: a Five-Year Retrospective Study
}

\author{
Jagoda Ravlić-Gulan ${ }^{1}$, Gordana Žauhar² \\ ${ }^{1}$ Department of Physiology, Immunology and Pathophysiology, Faculty of Medicine University of Rijeka, Rijeka, Croatia, \\ ${ }^{2}$ Department of Medical Physics and Biophysics, Faculty of Medicine University of Rijeka, Rijeka, Croatia, and Department of \\ Physics, University of Rijeka, Rijeka, Croatia
}

Correspondence: jravlic@medri.uniri.hr; Tel.: + 38551651 195; Fax.: + 38551675699

Received: 11 March 2020; Accepted: 7 April 2020

\begin{abstract}
Objective. To investigate whether the students' study-success correlates with the achievements evaluated in the enrolment process based on the State Graduation Exam. Methods. The retrospective study included a total of 637 students enrolled in the study of Medicine at the Faculty of Medicine from the academic year 2010-11 to 2014-15. We analysed the structure of students enrolled on the basis of the State Graduation Exam, examined their success in two courses of the study programme and then correlated this study-success with individual admission parameters. In particular, we investigated whether the success in the study was influenced by the changes made in the enrolment requirements during this period. Pearson's correlation coefficient was used to measure strenght of correlation between two variables. Results. The changes in the admission parameters, i.e., the inclusion of STEM subjects as obligatory enrolment requirements, made in 2012-13 enabled a better selection of students with high average secondary education grades and with significantly better results in Biology, Physics and particularly in Chemistry. This resulted in a higher success in the study, especially in the last two new-criteria generations. The Pearson correlation coefficient between students' success in Physiology and Pathophysiology II and the achievements valuated in enrolment procedure as total cumulative score were statistically significant $(\mathrm{r}=0.27, \mathrm{P}<0.001)$. Total points achieved in enrolment procedure was also correlated with students' success in Medical Physics and Biophysics and correlation was even stronger $(r=0.52, \mathrm{P}<0.001)$. Conclusion. Our results proved that a well-designed combination of the relevant admission parameters is a crucial prerequisite for a better success in the study.
\end{abstract}

Key Words: Enrolment • State Graduation Exam - Students' Study-Success.

\section{Introduction}

The State Graduation Exam (SGE) was first introduced in Croatia in the school year 2009-10 and has since been carried out by the National Centre for External Evaluation of Education (NCEEE) pursuant to a government decision. The primary aim of the introduction of the SGE was to establish standardized instruments for evaluating the learning outcomes achieved during secondary education in order to obtain measurable results and comparable performance indicators, and thus establish a mechanism for monitoring the achievement of educational objectives and thus assess the quality and/or identify the weaknesses of our educational system. Although the SGE was primarily conceived as a compulsory completion of grammar school ("certification" function), in the very first year of its introduction its results began to be used also for enrolment in study programs of higher education institutions (HEI) ("selectional" function), and thus became obligatory also for the students of four-year vocational and art schools who intended to continue their education at the tertiary level. This approach, however, disturbed the primary concept of state graduation, which was based on the students' obligation to take the level of subjects in the SGE that corresponded to the 
curriculum of their respective secondary school. This situation has forced experts to continuously review whether the SGE must have both the output and input function, and whether it is an equitable system for enrolment in higher education (1-5).

Despite these constant doubts, it is indisputable that the application of the results of SGE as enrolment criteria for HEI has a number of advantages: centralized online application; a better overview of study programmes being offered; the possibility of applying for up to 10 study programmes; all applicants simultaneously write the same standardized tests; a better transparency of the final results.

However, the specific reservations expressed regarding the "selection function" of the SGE led to HEI being given the responsible task of constantly analyzing their enrolment criteria. Indeed, every academic year, HEI have the obligation to submit their current enrolment criteria and scoring system for verification. In this way, the students' results achieved in various compulsory and elective subjects in the SGE can be evaluated, together with their previous achievements during secondary education. Moreover, admission to some study programmes was also dependent on additional verification of knowledge, skills and competencies, and it was also possible to set a number of other preconditions which could narrow the screening framework. It is assumed that, if properly assessed, each enrolment parameter is one of the important preconditions for future success in the study and acquisition of learning outcomes of each study programme.

Every year, 1400 or more high school graduates apply for admittance to the University of Rijeka, Faculty of Medicine (MedRi), which enrolls 130 new students for the study of Medicine per year. The candidates are ranked according to a scoring system, with a maximum of 1000 points. The original admission criteria, first determined in the year of inclusion of the SGE results, i.e., 201011 , have been changed only once, in the 2012-13 academic year. An overview of these two scoring systems implemented in the selection process for the study of Medicine at the MedRi throughout all investigated academic years is shown in Table
1. For all investigated generations of medical students, the grade point average (GPA) of the four-year secondary education accounted for $25 \%$ (250 points out of 1000), while the grades obtained in the SGE amounted to $75 \%$ (750 points out of 1000). However, the manner of distribution of the points awarded for the results in the graduation test was changed in the academic year 2012-13. Namely, in the first two years of admission to the study on the basis of the SGE results (2010-11 and 2011-12), we evaluated the results achieved in the mandatory SGE subjects (Croatian language 10\%, Mathematics $15 \%$, foreign language $10 \%$ ), all of which could have been taken at the basic level. An additional requirement for admission was just one elective subject (Biology, Chemistry or Physics), but if a candidate had passed all three elective subjects, their best result would be evaluated with $20 \%$ and the results of the other two subjects with 10\% each. In the academic year 2012-13, we introduced a new scoring system, still in use, in which we evaluate only the grades obtained in three elective subjects in the SGE: Biology (25\%), Chemistry (25\%) and Physics (25\%), all of which became mandatory for admission, with the remaining $25 \%$ still given for the secondary school GPA. We also included an additional precondition for admission, namely, compulsory previous attendance of Biology, Chemistry and Physics classes in at least two years of a secondary school program, and set the classification threshold at 400 points, below which no candidate can enrol. Our previous study (6) demonstrated some changes in the structure of students enrolled in the MedRi observed since the adoption of SGE results as enrolment criteria in relation to those previously enrolled on the basis of the entrance exam.

In the present study, we continued our previous research to determine how the introduction of the SGE, and particularly the changing of subjects taken into consideration for admission to the study of Medicine during this period, affected the quality of students enrolled, and whether there is a statistically significant correlation between the achievements valued in the admission process and the accomplishments of the learning outcomes 
Table 1. The Enrolment Requirements for the Study of Medicine at the Faculty of Medicine University of Rijeka in the Period from the Academic Year 2010/2011 to 2014/2015

\begin{tabular}{|c|c|c|c|c|c|}
\hline $\begin{array}{l}\text { Academic } \\
\text { year }\end{array}$ & Precondition & $\begin{array}{l}\text { Evaluation of } \\
\text { high school } \\
\text { grades }\end{array}$ & $\begin{array}{l}\text { Evaluation of mandatory } \\
\text { State Graduation } \\
\text { Exams }\end{array}$ & $\begin{array}{l}\text { Evaluation of elective } \\
\text { State Graduation Exams }\end{array}$ & $\begin{array}{l}\text { Classification } \\
\text { threshold }\end{array}$ \\
\hline $\begin{array}{l}2010 / 2011 \\
2011 / 2012\end{array}$ & - & $\begin{array}{l}25 \% \text { : high school } \\
\text { average grade } \\
\text { point }\end{array}$ & $\begin{array}{l}35 \% \text { : Croatian language } \\
(10 \%), \text { mathematics }(15 \%) \text {, } \\
\text { foreign language }(10 \%)\end{array}$ & $\begin{array}{l}40 \% \text { : one elective exam } \\
\text { (Biology or Chemistry or } \\
\text { Physics) was obligatory, } \\
\text { the best solved test was } \\
\text { evaluated for } 20 \% \text {, the } \\
\text { other two - each for } 10 \%\end{array}$ & - \\
\hline $\begin{array}{l}2012 / 2013 \\
2013 / 2014 \\
2014 / 2015\end{array}$ & $\begin{array}{l}\text { Compulsory attendance } \\
\text { of Biology, Chemistry } \\
\text { and Physics at least } \\
\text { two years of secondary } \\
\text { school program }\end{array}$ & $\begin{array}{l}25 \% \text { : High school } \\
\text { average grade } \\
\text { point }\end{array}$ & $\begin{array}{l}0 \% \text { : Croatian language }(0 \%) \text {, } \\
\text { mathematics }(0 \%) \text {, foreign } \\
\text { language }(0 \%) \text {; all exams } \\
\text { have to be passed, but } \\
\text { results are not evaluated }\end{array}$ & $\begin{array}{l}75 \% \text { : Biology (25\%), } \\
\text { Physics ( } 25 \%), \text { Chemistry } \\
\text { (25\%); all exams are } \\
\text { obligatory }\end{array}$ & $\begin{array}{l}400 \text { points } \\
\text { on the final } \\
\text { ranking }\end{array}$ \\
\hline
\end{tabular}

of two courses: Medical Physics and Biophysics $(\mathrm{MP} \& \mathrm{~B})$, and Physiology and Pathophysiology II (P\&PII), offered, respectively, in the first and second year of the study of Medicine.

\section{Methods}

Retrospective data collection was performed at the archives of the MedRi and included a total of 637 full-time students enrolled in the study of Medicine between the academic years 2010-11 and 2014-15. The data collection was approved by The Committee for Ethical Issues of the Faculty of Medicine. We studied five successive generations of medical students. The following data were used: secondary school GPA, State Graduation Exam results in Biology, Chemistry and Physics and total points achieved at entrance to study, success in the end-of-course (EOC) exams of MP\&B and P\&PII. Croatian educational system uses grades 1-5 for appraising knowledge, where 1 indicates failure and 5 is the highest grade. The study-success was measured by two indicators. Firstly, we analysed the success in the EOC exams of, respectively, MP\&B, which is taken in the first, and P\&PII, taken in the second year of the study. According to the University of Rijeka Rules on Studies, the following grades are used for the first three years of the study: A $80-100 \%$ excellent (5); B 70-79.9\%, very good (4); C 60-69.9\%, good (3); D 50-59.9\%, sufficient (2); E 40-49.9\%, sufficient (2); and FX and F, insufficient (1). For the purpose of correlation analysis, the SGE results and students' results of the two EOC exams were expressed in percentages. Students' performance was assessed with respect to the first two years of their studies. The five study groups were compared using the average values of variables for each group. The average grades were calculated on the basis of passed examinations only (grades 2-5).

Regarding the structure of enrolled students, we analysed how many of them had placed our study program high on the priority list in their online application (as their first or the second choice). According to the NCEEE rules, when applying for study programmes, the applicants can choose up to 10 programmes and the order of their choice in the final ranking list determines the study in which can enrol. If a candidate's total score on the final rankings is within the approved quotas for several study programmes, they have the right of entry only for the study which is placed highest on their priority list. We use this indicator as a measure of an applicants' interest for a specific study.

\section{Statistical Analysis}

Statistical analysis was performed using STATISTICA (StatSoft, Inc., Tulusa, OK, USA), version 13.1. The variables were tested for normality using Kolmogorov-Smirnov test. Continuous variables with normal distribution were expressed as mean 
\pm standard deviation (SD) and those with not normal distribution as median and interquartile range (IQR). Categorical variables were expressed as frequencies and corresponding percentages. Chi square-test was used for comparison of proportion of enrolled students who placed the study of Medicine as their first or the second choice on the priority list. The five study groups were compared in seven parameters (secondary GPA, SGE results in Biology, Chemistry and Physics, total points achieved at entrance to study and EOC exam results in MP\&B and P\&PII) using one-way analysis of variance (ANOVA) test, including post-hoc Scheffe test after testing for normal distribution. Pearson's correlation was used to investigate the association between the average grade obtained in the exams for the two relevant courses of the study of Medicine and the total skill score at admission to the study, as well as the results in the tests for elective subjects in the SGE. The statistical significance level was set at $\alpha=0.05 \quad(\mathrm{P}<0.05$ being considered statistically significant).

\section{Results}

\section{The Proportion of Enrolled Students Who Placed the Study of Medicine as Their First or the Second Choice on the Priority List}

We analysed (Figure 1) the proportion of enrolled students in five generations since the introduction of the SGE in the selection process who had placed the study of Medicine at the MedRi high on the priority list, i.e., as their first or the second choice. The five study groups were compared in the proportion of enrolled students who had placed the study of

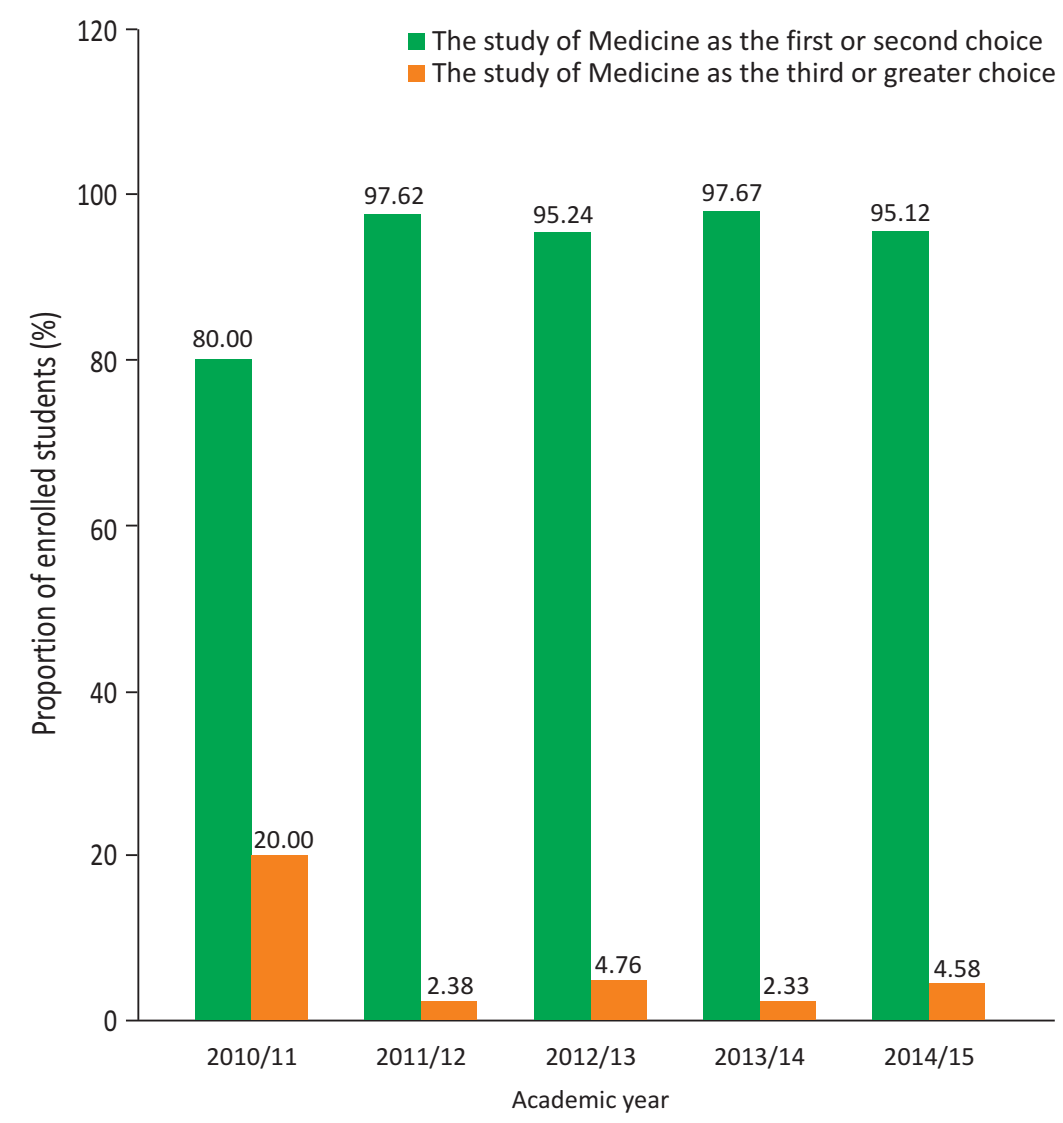

Figure 1. The place of the study of Medicine in Rijeka on the priority list of enrolled students. The proportion of enrolled students at the Faculty of Medicine University of Rijeka who set the study of Medicine as the first or the second choice (green bars) and the third or greater choice (orange bars) on the priority list in the period from the academic year 2010/2011 to 2014/2015. Values are expressed as percentages of enrolled students in particular academic year. 
Medicine at the MedRi high on the priority list and the analysis showed that there was a statistically significant difference (Chi-squared $=44.47$, $\mathrm{P}<0.001)$. Post hoc proportion test has shown that in the first generation the percentage of such students was significantly lower than in all four subsequent generations $(\mathrm{P}<0.001)$, although the difference between the subsequent four generations were not statistically different $(\mathrm{P}>0.05)$. Nevertheless, the change in the admission parameters made in the academic year 2012-13 did not significantly alter the percentage of students who had chosen our study of Medicine as their first or second choice when compared to the previous 2011-12 generation.

\section{The Structure of Students according to All Achievements Evaluated in the Enrolment Process}

\section{The Distribution of Students according to Their Secondary School Grade Point Average}

Throughout all academic years involved in the analysis, we enrolled excellent students with very high secondary-school GPA (Figure 2), ranging from 4.50 to 4.62 . We have noticed a slight but continuous increase in the secondary school GPA in the last three new-criteria generations (4.50; $4.58 ; 4.62)$, but the differences were not statistically significant in comparison to the former-criteria SGE-enrolled generations.

\section{The Distribution of Students Based on their Grades in Biology, Physics and Chemistry in the SGE}

The average percentage of correctly solved questions in the SGE Biology test (Figure 3A) ranged from $68.98 \%$ to $79.64 \%$, with the worst average grade in the first SGE-enrolled generation. A comparison of five generations with ANOVA test has shown that they differ significantly in their results on the SGE biology test $(\mathrm{F}=26.43, \mathrm{P}<0.001)$. Post hock analysis has shown that results in all the subsequent generations were statistically significantly better $(\mathrm{P}<0.001)$ than in the first generation. Actually, we observed that already in the first new-criteria generation, the results of SGE Biology test were significantly better than in the very first former-criteria SGE generation $(74.31 \%$ vs. $68.98 \%$; $\mathrm{P}<0.001)$, the last two new-criteria generations having significantly better

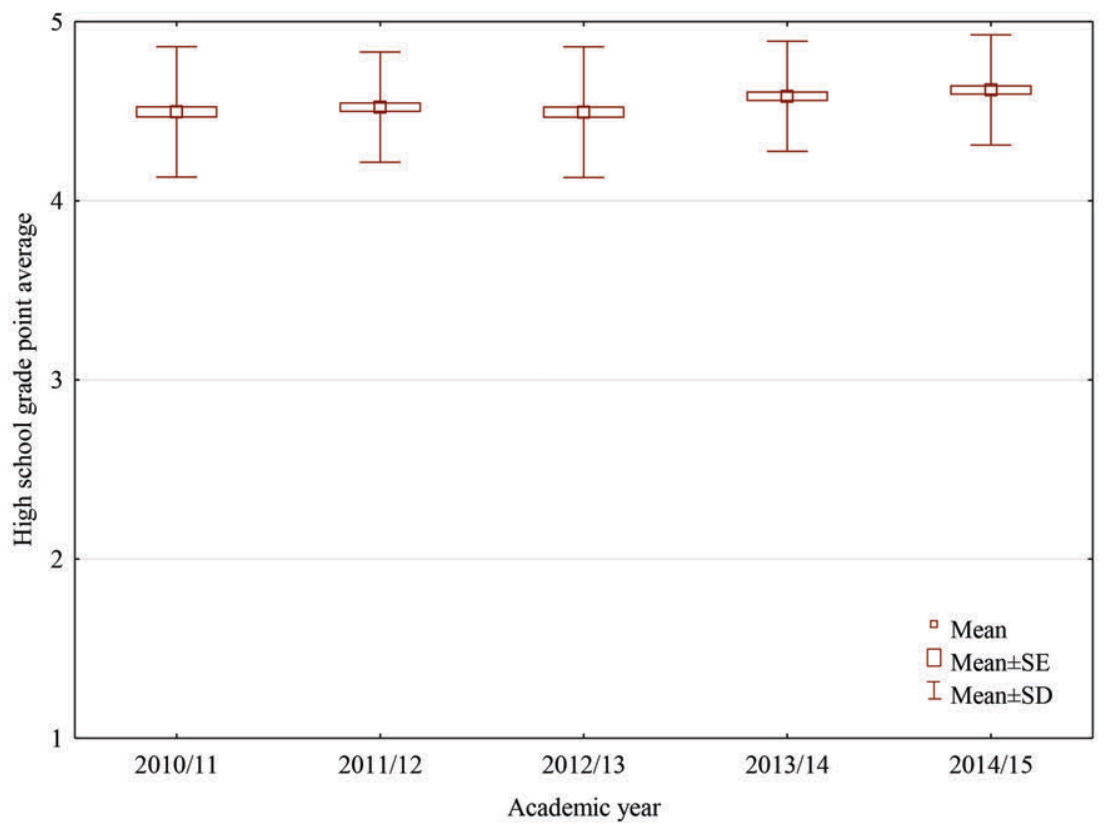

Figure 2. The high school grade point average of the enrolled students. The high school grade point average for the students enrolled in the study of Medicine at the Faculty of Medicine University of Rijeka in the period from the academic year 2010/2011 to 2014/2015. Grades are expressed as a mean \pm standard error (SE)/ standard deviation (SD). 
average grades even in comparison to the $2012-13$ one $(79.64 \%, \mathrm{P}<0.001$, and $77.97 \%, \mathrm{P}=0.016$ ).

Figure $3 \mathrm{~B}$ shows that the results of the SGE Physics test ranged from $51.78 \%$ to $71.6 \%$. Comparison of all five generations has shown that the difference in success in Physics at SGE is statistically significant ( $F=51.59, \mathrm{P}<0.001)$. The worst result in Physics was observed in the 2011-12 generation and was significantly lower $(\mathrm{P}<0.001)$ than the one achieved by the first SGE-enrolled generation (67\%). However, we observed that all three newcriteria generations had significantly better average results also in Physics (61.45\%; $65.7 \%$; 71.6\%; $\mathrm{P}<0.001)$ in comparison to the 2011-12 generation (51.78\%).

The results of the SGE Chemistry tests (Figure 3C) ranged from $46.33 \%$ to $70.93 \%$ for the investigated period. A comparison of five generations with ANOVA test has shown that they differ significantly in their results $(\mathrm{F}=144.08$, $\mathrm{P}<0.001)$. We observed that all three new-criteria generations had significantly better grades (66.25\%; 59.06\%; $70.93 \%$; $\mathrm{P}<0.001)$ compared to either of the two former-criteria SGE-enrolled generations (47.75\%; 46.33\%). Unlike Physics, the improvement in the Chemistry test results was not continuous over the years, but it is worth noting that the last analysed generation had significantly better $(\mathrm{P}<0.001)$ average results (70.93\%) in Chemistry compared to any previous generation.

Figure 3. The average success (percentages of correctly solved questions) in Biology, Physics and Chemistry at the State Graduation Exam. $\mathrm{A}=$ Biology; $\mathrm{B}=$ Physics; $\mathrm{C}=$ Chemistry at the State Graduation Exam for students enrolled in the study of Medicine at the Faculty of Medicine University of Rijeka in the period from the academic year 2010/2011 to 2014/2015. The results are expressed as a mean \pm standard error (SE)/ standard deviation (SD).
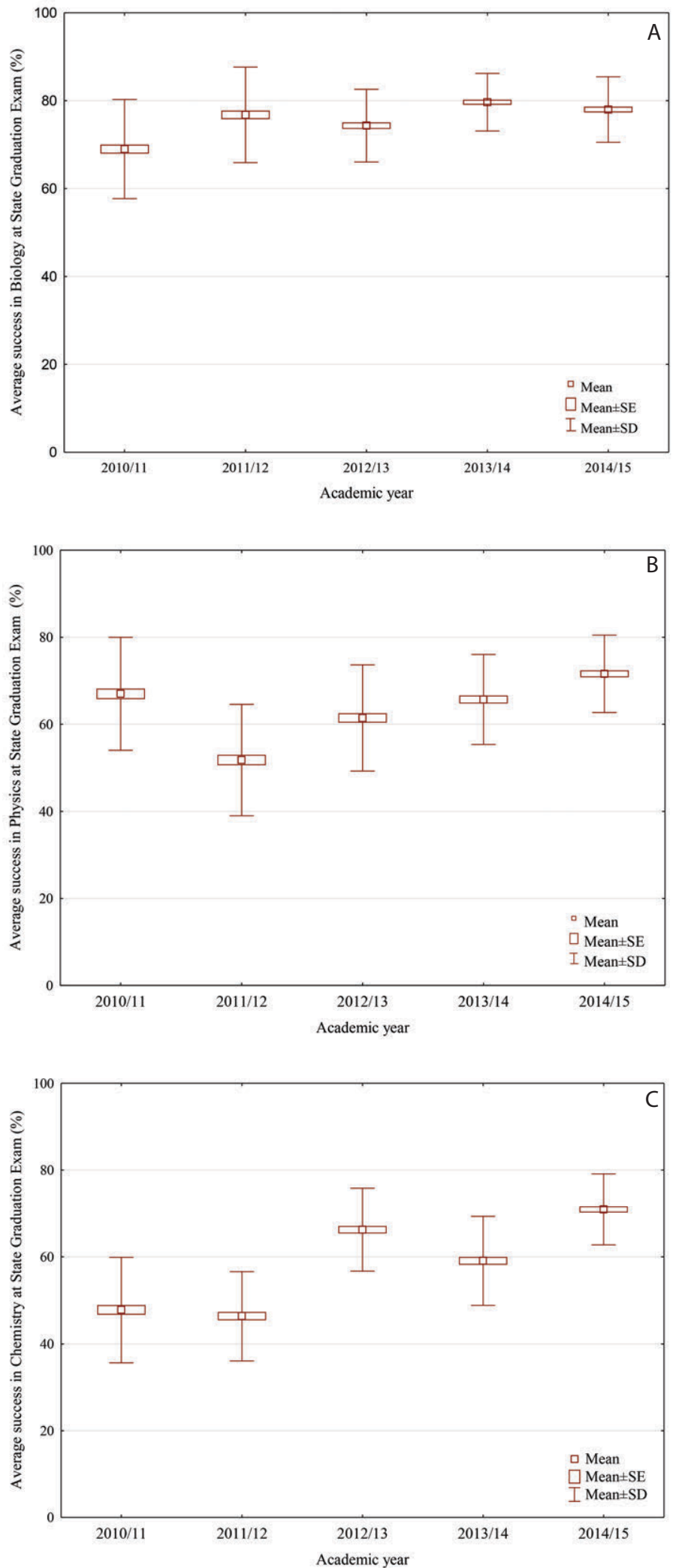


\section{The Comparison of the Total Score Achieved on the Basis of All Included Parameters of Evaluation}

The results of the total ranking score are shown on Figure 4, as median and interquartile range with the minimum and the maximum of all values on the ranking list. A continuous increase in the median value of total points throughout the analysed period was shown, starting from the first SGE generation. Comparison of all five generations has shown that the difference in success in total ranking score is statistically significant $(\mathrm{F}=39.69$, $\mathrm{P}<0.001)$. Although we have noticed that the total points (716.1) were higher already in the first newcriteria generation, the increase became statistically significant in the second new-criteria generation $(\mathrm{P}<0.001)$ in comparison to the former-criteria generations $(\mathrm{P}=0.017)$. An even more obvious increase in the total points was observed in the third new-criteria generation in comparison to either of the two former-criteria generations $(\mathrm{P}<0.001)$.

\section{The Students' Success in the Study of Medicine for the SGE-Enrolled Generations}

After a detailed analysis of the structure of students enrolled in the study of Medicine in five subsequent

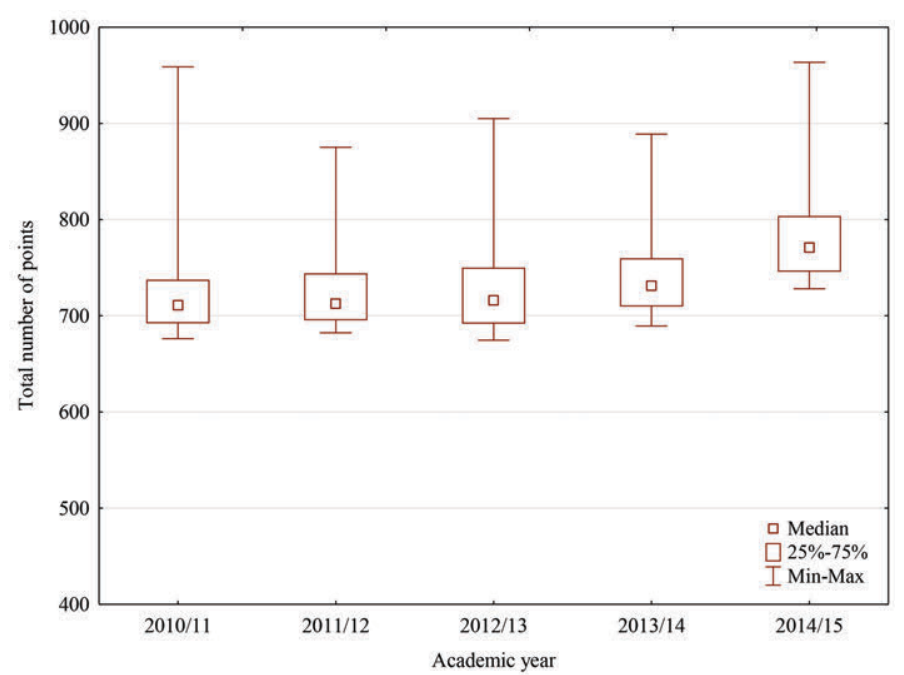

Figure 4. The total score on ranking list for students enrolled in the study of Medicine. The total number of points on final rankings for students enrolled in the study of Medicine at the Faculty of Medicine University of Rijeka in the period from the academic year 2010/2011 to $2014 / 2015$. Values are expressed as a median, interquartile range (IQR) and minimal and maximal values. generations starting from the introduction of the SGE in the selection process, we examined their success in studying and accomplishing the learning outcomes of two courses of the study programme: MP\&B in the first, and P\&PII in the second year of the study. The exam results for both courses are expressed as the average numerical grade calculated on the basis of passed examinations only (grades 2-5).

A comparison of the success in the EOC exam for $M P \& B$ is shown in Figure 5. To determine whether there is a statistically significant difference of mean grades between all academic years, oneway analysis of variance (ANOVA) test, including post-hoc Scheffe test was used. A comparison of all five generations in the success in the EOC exam for MP\&B has shown that the difference is statistically significant $(\mathrm{F}=16.98, \mathrm{P}<0.001)$. Although the data show that the average grade was higher already in the first new-criteria generation, post hock analysis has shown that the increase became statistically significant only in the second newcriteria generation in comparison to the 2010$11(\mathrm{P}=0.034)$ and the $2011-12$ ones $(\mathrm{P}=0.002)$. A more evident increase in the average grade was observed in the third new-criteria generation in comparison to both former-criteria generations $(\mathrm{P}<0.001)$. Moreover, the average score achieved in the EOC exam of MP\&B in the last three analysed generations became significantly higher from year to year.

Figure 6 shows a comparison of the success in the EOC exam of P\&PII in all analysed generations. Similar to the results in $M P \& B$, comparison of all five generations has shown that the difference in success on the EOC exam of P\&PII is statistically significant $(\mathrm{F}=7.15, \mathrm{P}<0.001)$. A continuous increase in the average grade in the EOC exam of P\&PII was also observed in all three new-criteria generations, but a statistically significant increase was observed only in the last two generations (2013-14, $\mathrm{P}=0.002$ and $2014-15, \mathrm{P}<0.001)$ in comparison to the last former-criteria SGE-enrolled generation. 
The respective differences between the average grades obtained in the EOC exams of MP\&B and of P\&PII were not statistically significant within the same generation of students. Moreover, the average grades in both courses showed a similar trend of increase in all three new-criteria generations. This seems to suggest that the results achieved in the exams of two different courses from the study programme are comparable, as the same generation of students achieved similar success in two separate courses in two consecutive years of study.

\section{The Correlation between the Results in the End-of-Course Exams of the Two Courses in the Study of Medicine and the Achievements Valued in the Selection Process}

In this study, we analysed whether there is a correlation between the results achieved in the EOC exams in two mandatory courses in the study programme of Medicine (MP\&B from the first, and P\&PII from the second year of the study) and any of the achievements valued in the selection process.

Figure 7 shows a statistically significant correlation between the results of this EOC exam in $M P \& B$ and all students' individual achievements valued in the classification procedure for almost all academic years. Thus, a significant correlation was observed between the secondary

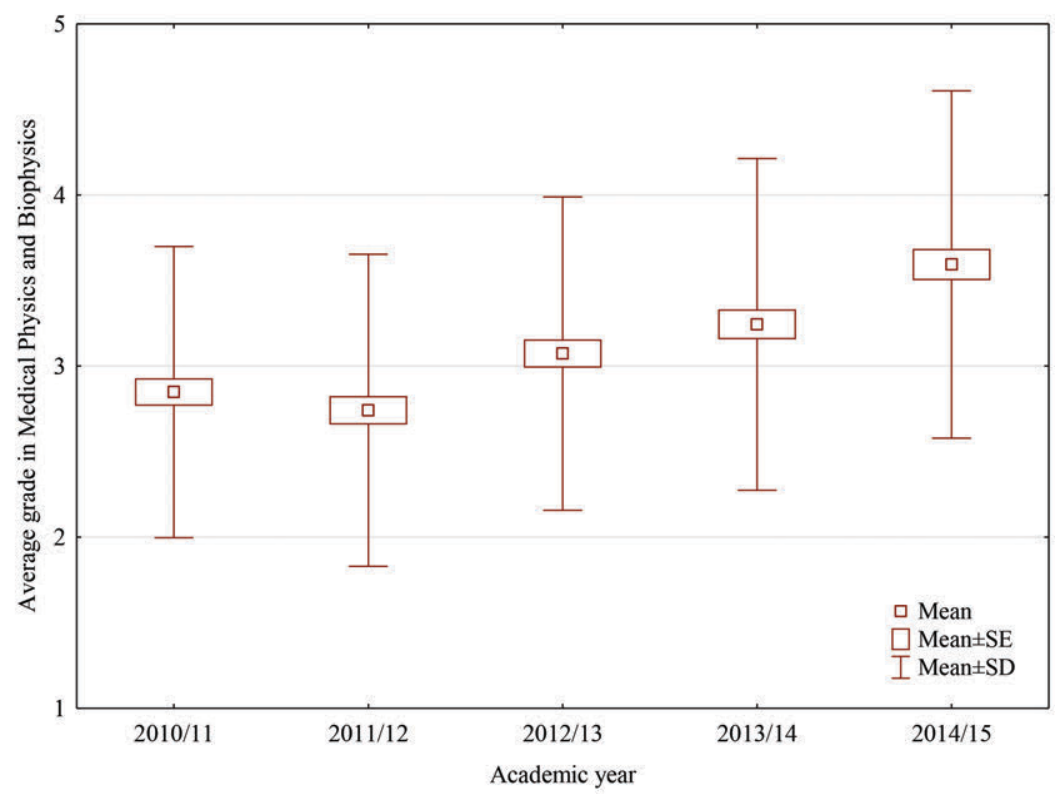

Figure 5. Students' success at the final exam of Medical Physics and Biophysics. The average grades at the final exam of Medical Physics and Biophysics in the first year of the study of Medicine at the Faculty of Medicine University of Rijeka in the period from the academic year 2010/2011 to 2014/2015. Passing grades (scale from 2 =sufficient to $5=$ excellent) are expressed as a mean \pm standard error (SE)/ standard deviation (SD).

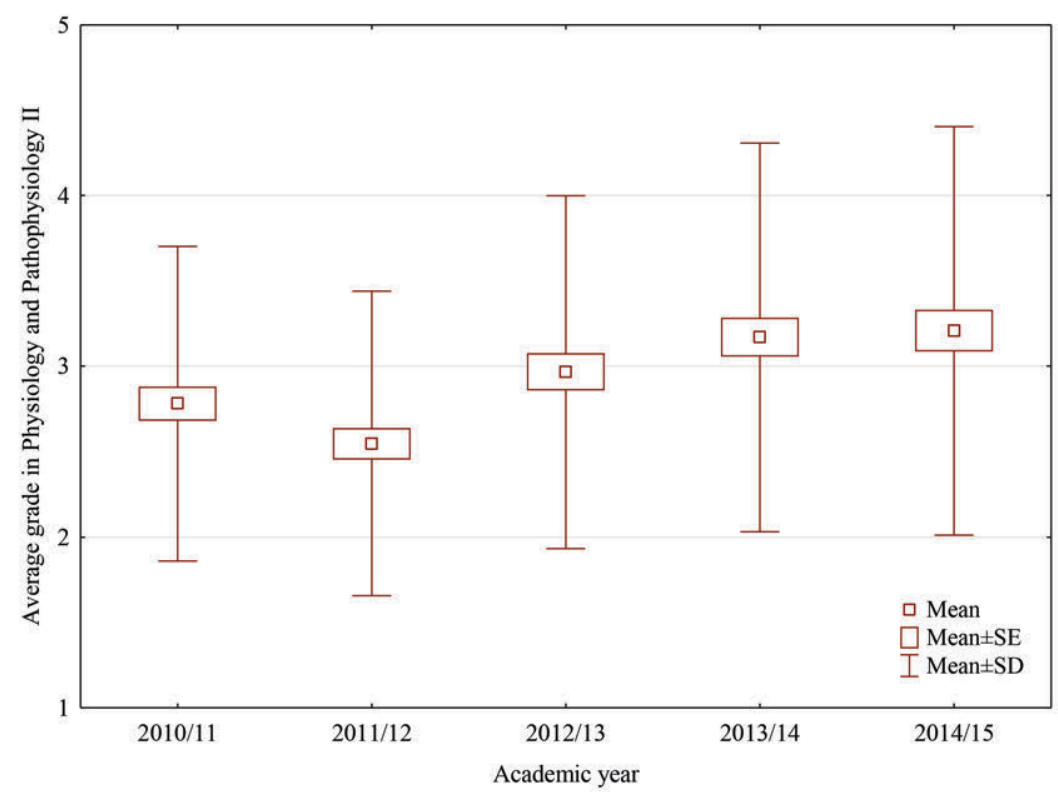

Figure 6. Students' success at the final exam of Physiology and Pathophysiology II. The average grades at the final exam of Physiology and Pathophysiology II in the second year of the study of Medicine at the Faculty of Medicine University of Rijeka in the period from the academic year 2010/2011 to 2014/2015. Passing grades (scale from $2=$ sufficient to $5=$ excellent) are expressed as a mean \pm standard error (SE)/ standard deviation (SD). 
school GPA and this EOC exam results in all analysed generations, while a correlation the students' success in this EOC exam and their individual results in the SGE Physics, Biology and Chemistry was

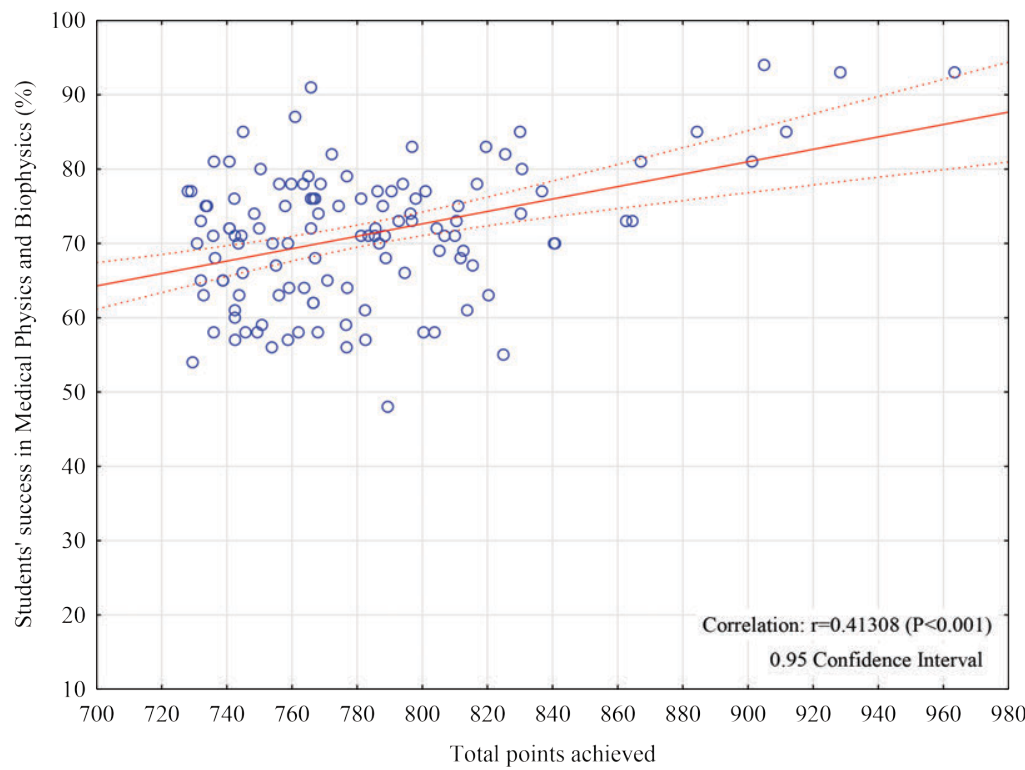

Figure 7. The correlation between State Graduation Exam results and students' success in Medical Physics and Biophysics. The correlation between the results of the final examination in Medical Physics and Biophysics and all individual achievements of students valued at classification to the study of Medicine at the Faculty of Medicine University of Rijeka in the academic year 2014/2015. Correlation was assessed using Pearson's test. found in some, but not all generations. Moreover, a significant correlation in all examined academic years was found between this EOC exam results and the overall score achieved in the SGE. In all examined academic years the highest value of the correlation coefficient was obtained between this EOC exam success and the total score on the ranking list (Table 2). The Pearson correlation coefficient between students' success in MP\&B and the achievements valuated in enrolment procedure as total cumulative score for all students who passed EOC exam were statistically significant $(\mathrm{r}=0.52, \mathrm{P}<0.001)$.

As regards P\&PII (Figure 8 ), a somewhat weaker correlation was obtained between the success in this EOC exam and all individual results included in the final ranking at enrolment. In contrast, in several generations (2010-11, 2012-13, 2014-15), a positive correlation between this EOC exam re-

Table 2. The Correlation between Students' Success in Medical Physics and Byophysics and the Achievements Valued in Enrolment Procedure for the Study of Medicine at the Faculty of Medicine University of Rijeka in the Period from the Academic Year 2010/2011 to 2014/2015

\begin{tabular}{|c|c|c|c|c|c|c|c|c|c|c|}
\hline \multirow{3}{*}{$\begin{array}{l}\text { Performance } \\
\text { parameters }\end{array}$} & \multicolumn{10}{|c|}{ Academic Year } \\
\hline & \multicolumn{2}{|c|}{ 2010/11 } & \multicolumn{2}{|c|}{$2011 / 12$} & \multicolumn{2}{|c|}{$2012 / 13$} & \multicolumn{2}{|c|}{$2013 / 14$} & \multicolumn{2}{|c|}{$2014 / 15$} \\
\hline & $r$ & $P$ & $r$ & $\mathrm{P}$ & $r$ & $P$ & $r$ & $P$ & $r$ & $\mathrm{P}$ \\
\hline $\begin{array}{l}\text { High school grade } \\
\text { point average }\end{array}$ & 0.351 & $<0.001$ & 0.302 & 0.002 & 0.220 & 0.015 & 0.323 & $<0.001$ & 0.347 & $<0.001$ \\
\hline $\begin{array}{l}\text { Biology at State } \\
\text { Graduation Exam }\end{array}$ & 0.263 & 0.008 & 0.071 & 0.475 & 0.199 & 0.028 & -0.006 & 0.945 & 0.188 & 0.039 \\
\hline $\begin{array}{l}\text { Physics at State } \\
\text { Graduation Exam }\end{array}$ & 0.258 & 0.009 & 0.443 & $<0.001$ & 0.273 & 0.002 & 0.232 & 0.010 & 0.265 & 0.003 \\
\hline $\begin{array}{l}\text { Chemistry at State } \\
\text { Graduation Exam }\end{array}$ & 0.312 & 0.002 & 0.330 & $<0.001$ & 0.261 & 0.004 & 0.134 & 0.144 & 0.201 & 0.027 \\
\hline $\begin{array}{l}\text { State Graduation } \\
\text { Exam results }\end{array}$ & 0.496 & $<0.001$ & 0.479 & $<0.001$ & 0.386 & $<0.001$ & 0.217 & 0.017 & 0.329 & $<0.001$ \\
\hline $\begin{array}{l}\text { Total points } \\
\text { achieved }\end{array}$ & 0.594 & $<0.001$ & 0.529 & $<0.001$ & 0.453 & $<0.001$ & 0.328 & $<0.001$ & 0.413 & $<0.001$ \\
\hline
\end{tabular}

Correlation was assessed using Pearson's test. Statistically significant results $(P<0.05)$. 
sults and the results in the SGE Biology was found. Moreover, in these generations there is also a statistically significant correlation between the success in the EOC exam and the overall grade achieved in the SGE. Finally, a statistically significant correlation between the success in this EOC exam and the total score on the ranking list was found in all gen- erations (Table 3). The Pearson correlation coefficient between students' success in P\&PII and the achievements valuated in enrolment procedure as total cumulative score for all students who passed EOC exam were statistically significant $(r=0.27$, $\mathrm{P}<0.001)$.

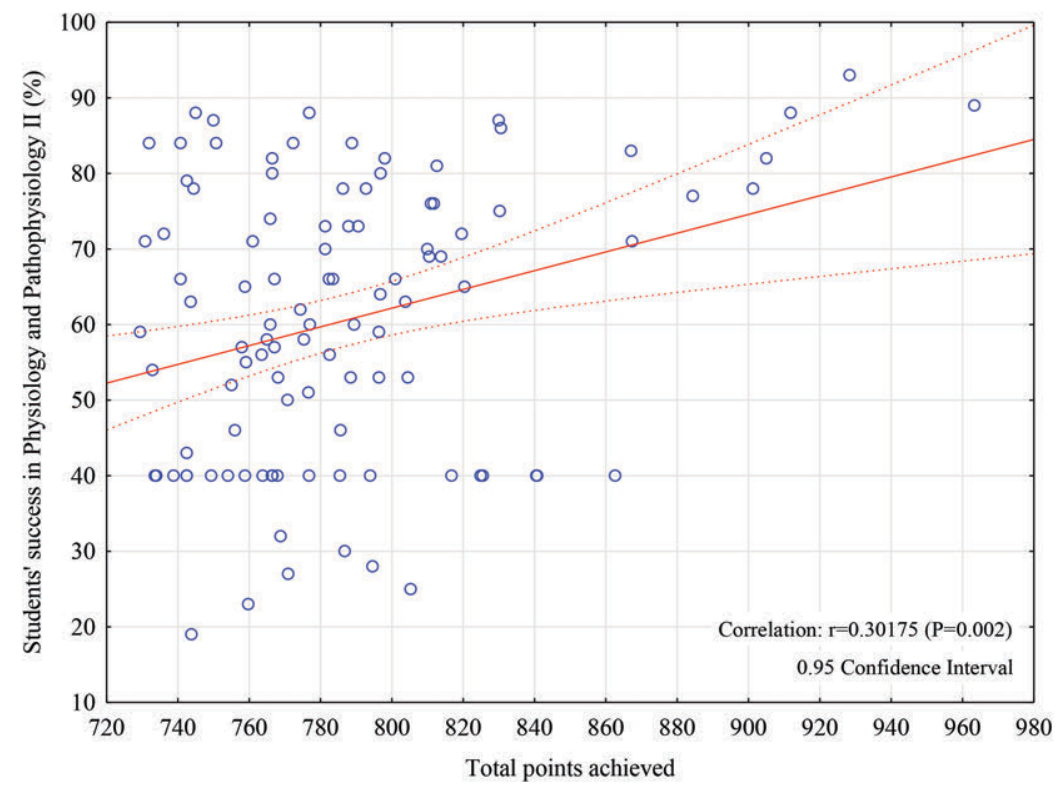

Figure 8. The correlation between State Graduation Exam results and students' success in Physiology and Pathophysiology II. The correlation between the results of the final examination in Physiology and Pathophysiology II and all individual achievements of students valued at classification to the study of Medicine at the Faculty of Medicine University of Rijeka in the academic year 2014/2015. Correlation was assessed using Pearson's test.

Table 3. The Correlation between Students' Success in Physiology and Pathophysiology II and the Achievements Valued in Enrolment Procedure for the Study of Medicine at the Faculty of Medicine University of Rijeka in the Period from the Academic Year 2010/2011 to 2014/2015

\begin{tabular}{|c|c|c|c|c|c|c|c|c|c|c|}
\hline \multirow{3}{*}{$\begin{array}{l}\text { Performance } \\
\text { parameters }\end{array}$} & \multicolumn{10}{|c|}{ Academic Year } \\
\hline & \multicolumn{2}{|c|}{$2010 / 11$} & \multicolumn{2}{|c|}{$2011 / 12$} & \multicolumn{2}{|c|}{$2012 / 13$} & \multicolumn{2}{|c|}{$2013 / 14$} & \multicolumn{2}{|c|}{$2014 / 15$} \\
\hline & $r$ & $\mathrm{P}$ & $r$ & $\mathrm{P}$ & $r$ & $\mathrm{P}$ & $r$ & $\mathrm{P}$ & $r$ & $\mathrm{P}$ \\
\hline $\begin{array}{l}\text { High school grade } \\
\text { point average }\end{array}$ & 0.185 & 0.103 & 0.215 & 0.051 & 0.103 & 0.293 & 0.183 & 0.057 & 0.241 & 0.014 \\
\hline $\begin{array}{l}\text { Biology at State } \\
\text { Graduation Exam }\end{array}$ & 0.291 & 0.009 & 0.029 & 0.788 & 0.362 & $<0.001$ & 0.106 & 0.271 & 0.249 & 0.011 \\
\hline $\begin{array}{l}\text { Physics at State } \\
\text { Graduation Exam }\end{array}$ & -0.005 & 0.966 & 0.221 & 0.045 & 0.051 & 0.606 & 0.035 & 0.714 & 0.127 & 0.200 \\
\hline $\begin{array}{l}\text { Chemistry at State } \\
\text { Graduation Exam }\end{array}$ & 0.197 & 0.081 & 0.180 & 0.103 & 0.090 & 0.357 & 0.185 & 0.055 & 0.085 & 0.389 \\
\hline $\begin{array}{l}\text { State Graduation } \\
\text { Exam results }\end{array}$ & 0.259 & 0.021 & 0.209 & 0.058 & 0.221 & 0.023 & 0.172 & 0.075 & 0.230 & 0.019 \\
\hline $\begin{array}{l}\text { Total points } \\
\text { achieved }\end{array}$ & 0.307 & 0.006 & 0.260 & 0.018 & 0.251 & 0.010 & 0.230 & 0.016 & 0.302 & 0.002 \\
\hline
\end{tabular}

Correlation was assessed using Pearson's test. Statistically significant results $(P<0.05)$. 


\section{Discussion}

In this study we found that one of the two enrolment regimes based on SGE, which is implemented in the academic 2012-13 year at the Faculty of Medicine in Rijeka, is proved to be a more successful screening method for our future students.

The introduction of the SGE in the school year 2009-10 has resulted in a series of changes in the education system of the Republic of Croatia. It was primarily designed as a tool for external evaluation of secondary education, but was at the same time adopted as an obligatory part in the classification procedure for enrolment in HEI. The selection role of the SGE has caused the most polemics in professional circles focused on the Croatian education system. Even before the implementation of the first SGE, the expert from the Centre for Educational Research and Development and the Institute for Social Research pointed to numerous inconsistencies in it (1). Some other important studies, published immediately after the implementation of the first SGE, analysed the results obtained in graduation exams in STEM subjects Mathematics, Biology, Chemistry and Physics, and discussed in detail the doubts that emerged from the experience gained from the first generation (25). The objections to the introduction of the SGE were mostly related to the inaccuracy in defining the exact aims of the SGE, which led to numerous difficulties, regarding either the determination of the test contents and the level of difficulty of graduation exams, or the analysis of the results of graduation exams in order to prepare useful recommendations for improving future exams.

In order to contribute to the analysis of the results and of possible consequences of introducing the SGE into the enrolment procedure for HEI, we continued our research published in the paper (6), which shown that this new method of selection has enabled easier enrolment for students from other Croatian counties and has significantly reduced enrolment of students from vocational schools, but has had no significant impact on the female to male ratio $(60: 40)$ in comparison to former enrolment through the Entrance Exam. In the present study we analysed the structure of enrolled students through some other indicators. The results showed that there was very high proportion of students in all analysed generations who placed our study programme on the top of their priority list, namely, as their first or second choice. In the first year of introduction of the SGE, $80 \%$ of students had placed our study of Medicine as the first or second choice, and in the following academic years this proportion was even significantly higher (95.24 to $97.67 \%$ ). Placing the study of Medicine high on the priority list reflects genuine motivation for enrolment, which certainly represents one of the most important parameters that influence the success in the study. Although other authors (7) describe the existence of several different categories of motivation for selection of a particular study, the six-year study of Medicine certainly does not belong in the category of the "less demanding" ones; most of the other reasons, for example the desire for a well-paid and respected job, the possibility of working abroad later on, etc., can only be encouraging for finishing the study within the prescribed period. Furthermore, we aimed to find whether the changes in the enrolment parameters made in the academic year 2012-13 have had any impact on the structure of enrolled students and their success in studying.

Our results showed that, regardless of the parameters used during the selection process, the screening of excellent high school students was continuously successful throughout the examined period (GPA varied from 4.50 to 4.62). We found a statistically significant positive correlation between the success in the first-year course in MP\&B and the secondary school GPA of enrolled students. However, although our results proved that the GPA achieved in secondary education is important and should be included among the parameters of classification because it evaluates the four-year secondary school success, we consider that GPA would not be good as the only parameter for selection because a more significant correlation was found between the success in the EOC exams of both examined subjects (MP\&B and P\&PII) and the overall score achieved on the basis of 
all evaluated parameters. This points to a higher importance of the knowledge demonstrated in the standardized SGE, which all applicants write at the same time. Kim et al. (8) proved the importance of GPA in predicting the study success, while the others emphasised that secondary school GPA, as an indicator of the habits of continuous work, seem to be more important for study success than one-time results in state graduation exams $(9,10)$. Moreover, there are a number of studies that claim that the importance of grades from secondary school, and even the results achieved in graduation tests, are subordinated to other important and desirable personality characteristics which, according to them, should be assessed by various experts in the selection process and could be crucial in the future professional work as a medical doctor (possession of inter- and intra-personal skills, communication skills, motivation, stress tolerance, empathy, academic excellence, etc.) (11-20).

Analysis of the students enrolled in our faculty on the basis of their achievements in individual SGE tests in Biology, Physics and Chemistry showed that the last three new-criteria generations had significantly better results in Biology in comparison to the very first former-criteria SGEenrolled generation, had significantly better results in Physics in relation to the second formercriteria SGE-enrolled generation, and finally, had significantly better results in Chemistry in relation to both former-criteria SGE-enrolled generations. However, the conclusions obtained by this analysis should be viewed in the context of all other changes that accompanied the classification process based on the state graduation. In detailed recommendations of Ristic Dedić et al. in 2011 (2-5), published after the first year of successful implementation of the SGE, the need to improve the contents and quality of test materials used in the selection to HEI was suggested. The authors have emphasized that for the selection purpose it is less important whether the test content is in compliance with the high school program, but greater attention should be paid if certain thematic areas and contents covered by the test are relevant for continuing education in a particular study programme.
Our analysis also showed a slight increase in the total number of points achieved already by the first new-criteria generation and, furthermore, a continuous and statistically significant increase in the subsequent generations. We believe that the new parameters of enrolment may serve as a powerful tool to select the best candidates. Our results also confirmed that the requirements for entry have been well chosen, and that simultaneous evaluation of the success in high school and the success in the state graduation tests in the ratio (25\%:75\%) ensures a good basis for successful accomplishment of learning outcomes later in the study.

In our previous analysis (6), we have already examined the students' study success for five generations enrolled on the basis of SGE by following up the average passing grade at EOC exam in $M P \& B$, a course taken in the first year of the study, and compared the results with those achieved by the last generation enrolled on the basis of the Entrance Exam in 2009-10. In the present study, we continued to monitor the success of these students in P\&PII, a course in the second year of the study. We have also compared the success in these two courses with each other and, additionally, examined if there is a correlation between the students' course success and their achievements in the SGE. Although in both courses we have noticed a continuous increase in the average passing grade in all three new-criteria enrolled generations, a statistically significant increase was found only in the last two generations (2013-14 and 2014-15) in comparison with any one or both former-criteria generations. The average passing grades for either course did not differ significantly within the same generations. Such findings have strengthened our assumption that better passing grades in the EOC exams for generations enrolled under the new parameters can be attributed to a better selection of high quality students that we have achieved by changing these parameters.

Regression analysis of the data from the enrolment and analysis of the passing grades at EOC exams showed a statistically significant correlation between the students' study success in the first and second year and the cumulative results they had 
achieved in SGE tests, and in particular with the total score obtained in the admission selection process. We have shown that the success in MP\&B in the first year of the study also correlated significantly with the results of each particular criteria parameter in almost all analysed generations, confirming our assumption that the selection process must evaluate exactly those secondary school achievements which will provide a good basis for easier accomplishment of the learning outcomes of the first-year subjects, mostly considered as a continuation of the secondary education with aim of creating a wider basis for all subsequent medical contents. As well, our regression analysis of results also showed that in all generations success in the exam of P\&PII correlates significantly with the student's overall results in the SGE tests, as well as with the total score in the admission selection process. This supports our assumption that a properly selected combination of enrolment parameters is also very important for accomplishing the learning outcomes of the subjects in the second year of study but, nevertheless, much more important are the competencies and skills acquired at the end of all medical courses in the first year of the study.

Although our results clearly revealed some positive changes in the students' success after the introduction of the SGE in the enrolment procedure, the fact is that our study has some limitations and that the success in the study cannot be associated exclusively either with the average passing grade achieved in the EOC examination in only two courses or with the enrolment parameters. Indeed, numerous other factors, both individual and institutional, influence the study success (21-24). The impact of paying tuition on academic performance, for instance, has also been analysed, but has not been found to present a stimulus for better studying in state-owned schools $(25,26)$.

The importance of several other factors should also be emphasised, among them the manner of assessment of the learning outcomes, the level of achieved objectivity in the EOC exams and the high-set criteria that prevent "inflation of passing grades" (27). Further investigations should include students' performance in other courses, especially in those that represent a significant barrier to studying and a common reason for interrupting the study of Medicine (Anatomy, Pathology, etc.) because of the complexity and scope of the contents, and we should correlate the outcomes achieved with the enrolment parameters. Moreover, other indicators of students' success should be found and put in correlation with the enrolment parameters of evaluation.

\section{Conclusion}

Our analysis showed that the changes in the enrolment parameters, namely, the introduction of the three STEM subjects as compulsory components of the ranking criteria in the academic year 201213, continued to provide an even better selection of students with a high average grade achieved in secondaryeducation, as wellas a selection of students with significantly better fundamental knowledge in STEM subjects (Biology, Physics and in particular Chemistry). This resulted in improved success in the study, especially in the last two generations of students enrolled under the new conditions of admission. For MP\&B, a course offered in the first year of the study, we have found a significant correlation between the success in the study and either individual or combined achievements which were evaluated at admission, while the success in the second-year course in P\&PII correlated significantly only with combined results of all SGE tests, as well as with the total cumulative score of all evaluated achievements. Our results supported the assumptions that the changes of the conditions of entry in 2012-13 had been well considered and that they had a better selection role in admission to the study of Medicine in comparison to previous parameters of evaluation. Our results also point to the great responsibility that HEI have for students' study-success, not only for their role in maintaining and improving the quality of teaching, but also because for their role in determining the relevant parameters for selection of students. 


\section{What Is Already Known on the Topic:}

Although the State Graduation Exam was primarily designed as a compulsory completion of grammar school and a tool for external evaluation of secondary education, it was adopted from the start as an obligatory part in the classification procedure for enrolment in higher education institutions. However, its dual role constantly provokes polemics in professional circles focused on the Croatian education system.

\section{What this Study Adds:}

In the present study, a statistically significant correlation between enrolment criteria and students' success in the study of Medicine was obtained, and thus we provided a scientific evidence that properly selected admission parameters could have a significant impact on future success in the study, which implies that higher education institutions have the great responsibility in determining the relevant parameters for selection of students.

Acknowledgement: The data were collected from the files of the Department of Medical Physics and Biophysics, the Department of Physiology, Pathophysiology and Immunology, and from the computer database of the University of Rijeka, Faculty of Medicine.

Authors' Contributions: Conception and design: JRG and GŽ; Acquisition, analysis and interpretation of data: JRG and GŽ; Drafting the article: JRG and GŽ; Revising it critically for important intellectual content: JRG and GŽ; Approved final version of the manuscript: JRG and GŽ.

Conflict of Interest: The authors declare that they have no conflict of interest.

\section{References}

1. Bezinović P. State Graduation Examination as an Obstacle to the Access to Higher Education [in Croatian]. Rev soc polit. 2009;16(2);175-6.

2. Ristić Dedić Z, Jokić B, Šabić J. Analysis of the content and the results of the state graduation exam in chemistry [in Croatian]. 1st ed. Zagreb: Nacionalni centar za vanjsko vrednovanje obrazovanja i Institut za društvena istraživanja u Zagrebu; 2011.

3. Ristić Dedić Z, Jokić B, Šabić J. Analysis of the content and the results of the state graduation exam in biology [in Croatian]. 1st ed. Zagreb: Nacionalni centar za vanjsko vrednovanje obrazovanja i Institut za društvena istraživanja u Zagrebu; 2011.

4. Ristić Dedić Z, Jokić B, Šabić J. Analysis of the content and the results of the state graduation exam in physics [in Croatian]. 1st ed. Zagreb: Nacionalni centar za vanjsko vrednovanje obrazovanja i Institut za društvena istraživanja u Zagrebu; 2011.

5. Ristić Dedić Z, Jokić B. Analysis of the content and the results of the state graduation exam in matematics from 2009/2010 to 2011/2012) [in Croatian]. Poučak. 2013;14(54):4-21.
6. Žauhar G, Dresto-Alač B, Lekić A, Ravlić-Gulan J. The enrollment to higher education institutions of the University of Rijeka before and after the introduction of the State Graduation Exam [in Croatian]. Medicina fluminensis. 2016;52(1):102-15.

7. Habuš-Korbar A, Tepić N, Culig B, Luzar-Stiffler $\mathrm{V}$. Classification and profiles of students based on their motivations concerning higher education. CIT. 2011;19(4):209-14.

8. Kim T, Chang JY, Myung SJ, Chang Y, Park KD, Park WB, et al. Predictors of Undergraduate and Postgraduate Clinical Performance: A Longitudinal Cohort Study. J Surg Educ. 2016;73(4):715-20.

9. Munđar D, Keček D, Matotek D. Relationship between enrollment criteria and first-year students' studysuccess. In: Proceedings of the 3rd Human and Social Sciences at the Common Conference (HASSACC). 2015. [cited 2016 Oct 25]. Available from: https://bib.irb.hr/ datoteka/791000.Relationship_between_enro.pdf.

10. Cohen-Schotanus J, Muijtjens AM, Reinders JJ, Agsteribbe J, van Rossum HJ, van der Vleuten CP. The predictive validity of grade point average scores in a partial lottery medical school admission system. Med Educ. 2006;40(10):1012-19.

11. Weingartner RH. Selecting for medical school. J Med Educ. 1980;55(11):922-7.

12. Eckhert NL, Cronin EJ. Diversity in membership of medical school admissions committees. J Med Educ. 1984;59(8):634-42.

13. Alaki SM, Yamany IA, Shinawi LA, Hassan MH, Tekian A. Can Multiple Mini-Interviews Predict Academic Performance of Dental Students? A Two-Year Follow-Up. J Dent Educ. 2016;80(11):1376-83.

14. Abbiati M, Baroffio A, Gerbase MW. Personal profile of medical students selected through a knowledge-based exam only: are we missing suitable students? Med Edu Online. 201612;21:29705. doi: 10.3402/meo.v21.29705.

15. Schripsema NR, van Trigt AM, van der Wal MA, CohenSchotanus J. How Different Medical School Selection Processes Call upon Different Personality Characteristics. PLoS One. 2016;11(3):1-10.

16. Koenig TW, Parrish SK, Terregino CA, Williams JP, Dunleavy DM, Volsch JM. Core personal competencies important to entering students' success in medical school: what are they and how could they be assessed early in the admission process? Acad Med. 2013;88(5):603-13.

17. Mahon KE, Henderson MK, Kirch DG. Selecting tomorrow's physicians: the key to the future health care workforce. Acad Med. 2013;88(12):1806-11.

18. Siu E, Reiter HI. Overview: what's worked and what hasn't as a guide towards predictive admissions tool development. Adv Health Sci Educ. 2009;14(5):759-75.

19. Burmeister J, McSpadden E, Rakowski J, Nalichowski A, Yudelev M, Snyder M. Correlation of admissions statis- 
tics to graduate student success in medical physics. J Appl Clin Med Phys. 2014;15(1):4451.

20. McManus IC, Richards P. Admission for medicine in the United Kingdom: a structural model of background factors. Med Educ. 1986;20(3):181-6.

21. Gruppen LD, Stansfield RB. Individual and Institutional Components of the Medical School Educational Environment. Acad Med. 2016;91(11):S53-7. doi:10.1097/ ACM.0000000000001361

22. Pelaccia T, Viau R. Motivation in medical education. Med Teach. 2017;39(2):136-40.

23. Ferguson E, James D, Madeley L. Factors associated with success in medical school: systematic review of the literature. BMJ. 2002;324(7343):952-7.

24. McManus IC, Dewberry C, Nicholson S, Dowell JS. The UKCAT-12 study: educational attainment, aptitude test performance, demographic and socio-economic contextual factors as predictors of first year outcome in a crosssectional collaborative study of 12 UK medical schools. BMC Med. 2013;11:244. doi: 10.1186/1741-7015-11-244.

25. Prka M, Pulanić D, Glavaš E. Paying tuition and academic performance of students at the Zagreb University School of Medicine. Croat Med J. 2001;42(1):74-8.

26. McManus IC, Woolf K, Dacre J, Paice E, Dewberry C. The Academic Backbone: longitudinal continuities in educational achievement from secondary school and medical school to MRCP(UK) and the specialist register in UK medical students and doctors. BMC Med. 2013;11:242. doi: 10.1186/1741-7015-11-242.

27. Bergovac M, Kuzman T, Rojnic M, Makovic A. Is there grade inflation at medical schools? Case study of the Zagreb University School of Medicine. Croat Med J. 2003;44(1):92-7. 